\title{
Intensive versus moderate statin therapy and early graft occlusion after coronary bypass surgery: The Aggressive Cholesterol Therapy to Inhibit Vein Graft Events randomized clinical trial
}

\author{
Alexander Kulik, MD, MPH, ${ }^{a}$ Amy M. Abreu, MPA, BSN, RN, CCRC, \\ Viviana Boronat, MD, MBA, CCRP, ${ }^{a}$ and Marc Ruel, MD, MPH ${ }^{b}$
}

\section{ABSTRACT}

Objective: Statins prevent saphenous vein graft (SVG) disease and improve outcomes after coronary artery bypass graft surgery. However, the optimal postoperative statin dose remains unclear. The Aggressive Cholesterol Therapy to Inhibit Vein Graft Events trial was undertaken to evaluate whether early postoperative high-dose statin therapy reduces SVG occlusion compared with conventional moderate-dose therapy.

Methods: In this pilot, multicenter, double-blind randomized trial, 173 patients who had coronary artery bypass graft surgery with SVG were randomized to receive $10 \mathrm{mg}$ or $80 \mathrm{mg}$ atorvastatin daily for 1 year. The primary outcome was SVG occlusion at 1 year. Secondary outcomes were SVG stenosis and major adverse cardiovascular events.

Results: During trial enrollment, patients randomized to $80 \mathrm{mg}$ atorvastatin achieved significantly lower low-density lipoprotein cholesterol levels $(P<.00001)$. One-year graft assessment was performed in 145 patients $(83.8 \%)$. The primary outcome, SVG occlusion at 1 year, did not significantly differ between the 2 groups $(12.9 \%$ vs $11.4 \%$ for $10 \mathrm{mg}$ atorvastatin vs $80 \mathrm{mg}$ atorvastatin; $P=.85)$. The incidence of vein graft stenosis also did not significantly differ between the groups $(P=.54)$. However, there was a trend toward fewer patients developing vein graft disease (either occlusion or stenosis) in the $80 \mathrm{mg}$ atorvastatin group $(29.2 \%$ vs $19.2 \%, 10 \mathrm{mg}$ atorvastatin vs $80 \mathrm{mg}$ atorvastatin; $P=.18)$. Freedom from major adverse cardiovascular events at 1 year was similar between the groups $(P=.27)$.

Conclusions: Compared with $10 \mathrm{mg}$ atorvastatin, $80 \mathrm{mg}$ atorvastatin did not significantly reduce vein graft occlusion 1 year after coronary artery bypass graft surgery in this pilot trial. (J Thorac Cardiovasc Surg 2019;157:151-61)

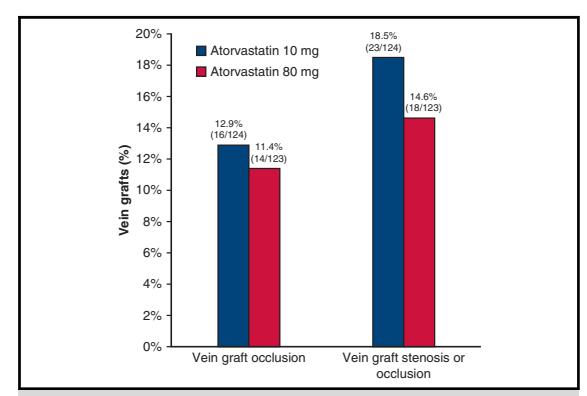

Atorvastatin $80 \mathrm{mg}$ did not significantly reduce the incidence of vein graft disease.

\section{Central Message}

In this pilot trial, $80 \mathrm{mg}$ atorvastatin did not significantly reduce 1 -year vein graft occlusion compared with $10 \mathrm{mg}$ atorvastatin.

\section{Perspective}

Statins prevent vein graft disease, but the optimal dose after $\mathrm{CABG}$ remains unclear. In this pilot trial, the 1 year vein graft occlusion rate did not significantly differ between patients randomized to receive atorvastatin at a dose of $10 \mathrm{mg}$ or $80 \mathrm{mg}$.

See Editorial Commentaries pages 162 and 164.

See Editorial page 147.

\footnotetext{
From the a Lynn Heart and Vascular Institute, Boca Raton Regional Hospital, and Charles E. Schmidt College of Medicine, Florida Atlantic University, Boca Raton, Fla; and ${ }^{\mathrm{b}}$ University of Ottawa Heart Institute, Ottawa, Ontario, Canada.

The ACTIVE trial was funded by an American Heart Association Grant-in-Aid Research Grant (awarded to Dr Kulik, No. 12GRNT12050027) and by the Division of Cardiac Surgery Endowed Research Chair of the University of Ottawa Heart Institute (Dr Ruel). Pfizer Inc provided the atorvastatin tablets, but did not financially support or contribute to the trial design.

Read at the 98th Annual Meeting of The American Association for Thoracic Surgery, San Diego, California, April 28-May 1, 2018.

Received for publication Dec 22, 2017; revisions received April 24, 2018; accepted for publication May 21, 2018; available ahead of print Aug 16, 2018.

Address for reprints: Alexander Kulik, MD, MPH, Lynn Heart and Vascular Institute, Boca Raton Regional Hospital, 800 Meadows Rd, Boca Raton, FL 33486 (E-mail: alex_kulik@yahoo.com).

$0022-5223 / \$ 36.00$

Copyright (c) 2018 by The American Association for Thoracic Surgery https://doi.org/10.1016/j.jtcvs.2018.05.123
}

During coronary artery bypass graft (CABG) surgery, the saphenous vein is the most commonly utilized conduit because of its ready availability. ${ }^{1-3}$ Although convenient for use at the time of surgery, limitations associated with the saphenous vein become apparent in the years that follow. Vein grafts

Uf Scanning this QR code will
take you to a supplemental
video and tables for the article.
To view the AATS Annual
Meeting Webcast, see the
URL next to the webcast
thumbnail.




\begin{tabular}{|c|c|}
\hline \multicolumn{2}{|c|}{ Abbreviations and Acronyms } \\
\hline ACTIVE & $\begin{aligned}= & \text { Aggressive Cholesterol Therapy to } \\
& \text { Inhibit Vein Graft Events Trial }\end{aligned}$ \\
\hline CABG & $=$ coronary artery bypass graft \\
\hline CK & $=$ creatine kinase \\
\hline CT & $=$ computed tomography \\
\hline IMPROV & $\begin{array}{l}=\text { Improved Reduction of Outcomes: } \\
\text { Vytorin Efficacy International } \\
\text { Trial }\end{array}$ \\
\hline LDL & $=$ low-density lipoprotein \\
\hline MACE & $\begin{aligned}= & \text { major adverse cardiovascular } \\
& \text { events }\end{aligned}$ \\
\hline SVG & $=$ saphenous vein graft \\
\hline
\end{tabular}

develop intimal hyperplasia and smooth muscle cell proliferation early after surgery, ultimately leading to atherosclerosis and graft occlusion. ${ }^{4-6}$ This process, termed saphenous vein graft (SVG) disease, appears to be intensified amongst patients with hyperlipidemia. ${ }^{7,8} \mathrm{Up}$ to $20 \%$ of SVGs may occlude within the first year following surgery. By 10 years after CABG, $40 \%$ of SVGs are occluded, and $50 \%$ of those that are patent have marked atherosclerosis. ${ }^{4,6}$ As a result of graft and native vessel attrition, patients who have undergone $\mathrm{CABG}$ are at risk for subsequent ischemic events, ${ }^{4,6}$ highlighting the importance of secondary preventive therapies after surgery. ${ }^{9-11}$ Statins play a key role in the postoperative medical care of patients undergoing CABG because they limit the progression of atherosclerosis in both native coronary arteries and SVGs, reduce postoperative cardiovascular events, and improve long-term survival. ${ }^{12-15}$

Based on the landmark post-CABG trial, ${ }^{12,13}$ clinical guidelines for many years have recommended statins after surgery with a target low-density lipoprotein (LDL) cholesterol treatment goal $<100 \mathrm{mg} / \mathrm{dL} .{ }^{16,17}$ More recently, several studies in the cardiology literature demonstrated that even more intensive lipid reduction with high-dose statin therapy may further improve cardiovascular outcomes. ${ }^{18-21}$ Post-hoc analyses from these trials have suggested that patients with a remote history of CABG may also benefit from high-dose statin therapy, ${ }^{18,22}$ but little data exist regarding the use of high-intensity statins immediately following CABG. ${ }^{23-25}$ As such, it remains unclear whether LDL cholesterol levels approaching $70 \mathrm{mg} / \mathrm{dL}$ can improve postoperative graft patency. ${ }^{26,27}$ To date, no clinical trial has evaluated whether high-dose statin therapy after CABG inhibits the process of SVG disease and improves graft patency. In the Aggressive Cholesterol Therapy to Inhibit Vein Graft Events (ACTIVE) trial, we conducted a randomized double-blinded study to explore the influence of early high-intensity statin therapy on the rate of vein graft occlusion 1 year after CABG compared with standard moderate-dose statin therapy, using computed tomography (CT) coronary angiography. Secondary end points included vein graft stenosis, major adverse cardiovascular events (MACEs), and safety outcomes.

\section{METHODS \\ Study Population}

The ACTIVE trial was conducted at the Lynn Heart and Vascular Institute of Boca Raton Regional Hospital (Boca Raton, Fla) and the University of Ottawa Heart Institute (Ottawa, Ontario, Canada) between March 2012 and January 2017. Patients were eligible for study enrollment if they underwent first-time multivessel CABG with at least 1 SVG. Endoscopic SVG harvesting was the predominant technique used in the study. Patients undergoing either on-pump or off-pump CABG were included. The institutional review board of each participating surgical center approved the study protocol. The study was also reviewed and approved by the Food and Drug Administration and by Health Canada. Each patient provided written informed consent before enrollment.

\section{Study Design}

Clinical trial registration is at ClinicalTrials.gov (identifier No. NCT01528709) and institutional review board approval was obtained from the Boca Raton Regional Hospital Institutional Review Board (study No. 2011.02).

Details of the study design have previously been published. ${ }^{28}$ Briefly, patients were randomly assigned in the postoperative period to receive either $10 \mathrm{mg}$ atorvastatin daily (moderate-dose statin therapy) or $80 \mathrm{mg}$ atorvastatin daily (high-dose statin therapy), starting within 5 days of surgery, for the duration of 1 year. The atorvastatin study medications appeared identical for the purpose of blinding in this study. Preoperative lipid medications (including statins, niacin, fibrate, or ezetimibe) were all discontinued after study enrollment to ensure a standardized postoperative lipid-lowering regimen by using the trial medication only. Patients received concomitant therapies in both groups as recommended by contemporary American College of Cardiology/American Heart Association guidelines over the duration of the trial. This included smoking cessation counseling and the administration of antiplatelet agents, anticoagulants, beta blockers, and angiotensin converting enzyme inhibitors, as indicated. ${ }^{16,17}$ In keeping with usual practice, aspirin was prescribed for all patients after CABG. Following off-pump CABG, clopidogrel was added to aspirin for at least 1 month postoperatively. ${ }^{9,29}$

After hospital discharge, patients were followed with a physician clinic visit at 1 month, and research coordinator visits thereafter at 3, 6, 9, and 12 months after surgery, to document any MACEs and to encourage study drug compliance. Laboratory assessments (including a fasting lipid profile, liver function tests, and a creatine kinase [CK] level) were performed before study drug initiation and at months $3,6,9$, and 12 . At 1 year, patients returned for a creatinine level measurement and a postoperative CT coronary angiogram to assess graft patency. Compared with conventional coronary angiography, CT angiography has a favorable sensitivity and specificity for the assessment of vein graft occlusion, and yet is less invasive and less likely to lead to patient test refusal. ${ }^{30}$

This trial was designed as a pilot study and was not powered as a definitive clinical trial. Outcome estimates from this study could then inform the design of a larger definitive trial, should interest and support for such an initiative remain thereafter. One hundred patients in each study arm were to be enrolled, with a planned total of 200 patients. However, the investigators decided to close the trial after recruitment of 173 patients due to slow study enrollment and the recent publication of new clinical guidelines recommending high-intensity statin therapy for essentially all patients after CABG. ${ }^{9,28,31}$

\section{Randomization and Masking}

Randomization was stratified according to the surgical center, the presence or absence of diabetes mellitus, and the use or nonuse of 
cardiopulmonary bypass during CABG. A block randomization schedule was generated using SAS version 9.1 software (SAS Institute Inc, Cary, NC). All patients and study personnel were blinded to the treatment assignment.

Clinical guidelines in place at the time of trial development recommended statin treatment to achieve LDL levels of $100 \mathrm{mg} / \mathrm{dL}$ or less after CABG. ${ }^{16,17}$ However, it remained possible that a few patients randomized to receive $10 \mathrm{mg}$ atorvastatin daily would not achieve this postoperative target LDL level of $100 \mathrm{mg} / \mathrm{dL}$. As such, to ensure that all study subjects received the standard of care (based on the guidelines at that time), an escape criterion was incorporated into the trial. Patient unblinding occurred for patients who had LDL levels $>115 \mathrm{mg} / \mathrm{dL}$ at the 3- or 6-month time point after surgery. Such patients then had their atorvastatin dose increased or an alternative statin was substituted in open label fashion for the remainder of their enrolment in the trial. Imaging and outcome assessment at 1 year continued for these patients per study protocol, despite unblinding.

\section{Outcomes}

The primary outcome of the study was vein graft occlusion 1 year after surgery using CT coronary angiography, defined as the absence of contrast opacification throughout the entire length of a graft. Secondary outcomes included vein graft stenosis $(50 \%$ or greater narrowing of the graft lumen diameter), vein graft disease (stenosis or occlusion), as well as MACE (eg, cardiovascular death, myocardial infarction, cerebrovascular accident, hospitalization for coronary ischemia, or need for coronary intervention). CT readings were performed at each participating center by radiologists (blinded to treatment allocation) with expertise in CT coronary angiography. Safety outcomes included elevations in levels of aspartate aminotransferase or alanine aminotransferase higher than 3 times the upper limit of normal; myopathy, defined as a CK level > 10 times the upper limit of normal associated with muscle symptoms; and rhabdomyolysis, defined as $\mathrm{CK}>10,000 \mathrm{U} / \mathrm{L}$, with or without muscle symptoms. ${ }^{18-21}$

\section{Statistical Analysis}

Baseline characteristics and follow-up measures were compared according to the study-group assignment at randomization. Clinical outcomes were compared on an intention-to-treat basis. Vein graft occlusion and other categorical variables were compared between the study groups by using a Fisher exact test. Continuous variables were compared with a 2 -sided Student $t$ test or with a 2-sample Wilcoxon signed-rank test, as appropriate. A repeated measures analysis of variance was used to compare LDL cholesterol levels between the 2 groups over the duration of the trial, with adjustment for baseline values. Time to MACE was determined for the study groups by using the Kaplan-Meier method, with standard errors estimated by using Greenwood's formula. Groups were compared with a log-rank test. All reported $P$ values are 2-sided.

Further analysis was performed using logistic regression analysis to adjust for randomization stratification factors (eg, surgical center, the use of cardiopulmonary bypass, and the presence of diabetes) or factors that differed between the 2 groups despite randomization (ie, age). To account for within-patient correlation and the possibility of multigraft occlusion within individual patients, vein graft data were also analyzed by using generalized estimating equations. Finally, a per-protocol analysis was performed, focusing only on patients who completed the trial and did not discontinue the allocated medication (either temporarily or permanently) during study enrollment.

\section{RESULTS \\ Patients}

From March 2012 to January 2016, 173 patients were randomly assigned to receive either $10 \mathrm{mg}$ atorvastatin daily
(87 patients, 235 total grafts) or $80 \mathrm{mg}$ atorvastatin daily ( 86 patients, 249 total grafts) (Figure 1). The use of medications at baseline and demographic characteristics were similar in the 2 treatment groups, except for patient age $(P=.05)$ (Table 1). Patients randomized to $80 \mathrm{mg}$ atorvastatin more often received a second arterial graft at the time of surgery $(P=.03)$, but other operative characteristics were similar between the 2 groups. Postoperatively, the use of medications did not differ between the 2 groups (Table 2). The majority of patients received aspirin and beta blocker therapy after CABG.

At the time of study enrollment, baseline LDL cholesterol levels were similar between the 2 groups $(83.2 \pm 31.7 \mathrm{mg} / \mathrm{dL}$ vs $80.2 \pm 33.2 \mathrm{mg} / \mathrm{dL}$ for $10 \mathrm{mg}$ atorvastatin vs $80 \mathrm{mg}$ atorvastatin; $P=.56$ ). During the course of trial, LDL cholesterol levels declined further in patients who received $80 \mathrm{mg}$ atorvastatin compared with those who received $10 \mathrm{mg}$ atorvastatin (Figure 2) (analysis of variance $P<.0001$ ). Following study enrollment, the mean LDL cholesterol level for the $10 \mathrm{mg}$ atorvastatin group was $79.2 \pm 19.7 \mathrm{mg} / \mathrm{dL}$ compared with $58.5 \pm 20.4 \mathrm{mg} / \mathrm{dL}$ for the $80 \mathrm{mg}$ atorvastatin group (26.1\% relative reduction; $P<.00001)$.

\section{CT Coronary Angiography}

One-year CT coronary angiography was completed for 72 patients $(82.8 \%)$ in the $10 \mathrm{mg}$ atorvastatin group, and 72 patients $(83.7 \%)$ in the $80 \mathrm{mg}$ atorvastatin group. One additional patient in the $80 \mathrm{mg}$ atorvastatin group underwent a conventional coronary angiogram just before the 1-year time point due to chest pain symptoms. All together, 403 grafts were examined by imaging. The 1 -year overall graft occlusion rate for the entire cohort was 9.9\% (40 out of 403). The overall vein graft occlusion rate was $12.1 \%$ (30 out of 247).

As shown in Table 3, the primary outcome of the trial, vein graft occlusion at 1 year, did not significantly differ between the 2 groups $(12.9 \%$ vs $11.4 \%, 10 \mathrm{mg}$ atorvastatin vs $80 \mathrm{mg}$ atorvastatin; $P=.85$ ). The 1 -year overall graft occlusion rate was $10.3 \%$ in the $10 \mathrm{mg}$ atorvastatin, and $9.6 \%$ in the $80 \mathrm{mg}$ atorvastatin group $(P=.87)$. The incidence of vein graft stenosis also did not differ between the groups ( $5.6 \%$ vs $3.2 \%$ for $10 \mathrm{mg}$ atorvastatin vs $80 \mathrm{mg}$ atorvastatin; $P=.54$ ) (Figure 3). Although this was not a prespecified end point, there was a trend toward fewer patients developing vein graft disease (either occlusion or stenosis) in the $80 \mathrm{mg}$ atorvastatin group $(29.2 \%$ vs $19.2 \%, 10 \mathrm{mg}$ atorvastatin vs $80 \mathrm{mg}$ atorvastatin; $P=.18$ ).

\section{Clinical Outcomes}

Table 4 summarizes the study clinical outcomes, adverse events, and reasons for study medication discontinuation. All together, MACEs occurred in 2 patients $(2.3 \%)$ from the $10 \mathrm{mg}$ atorvastatin group and 5 patients $(5.8 \%)$ from 


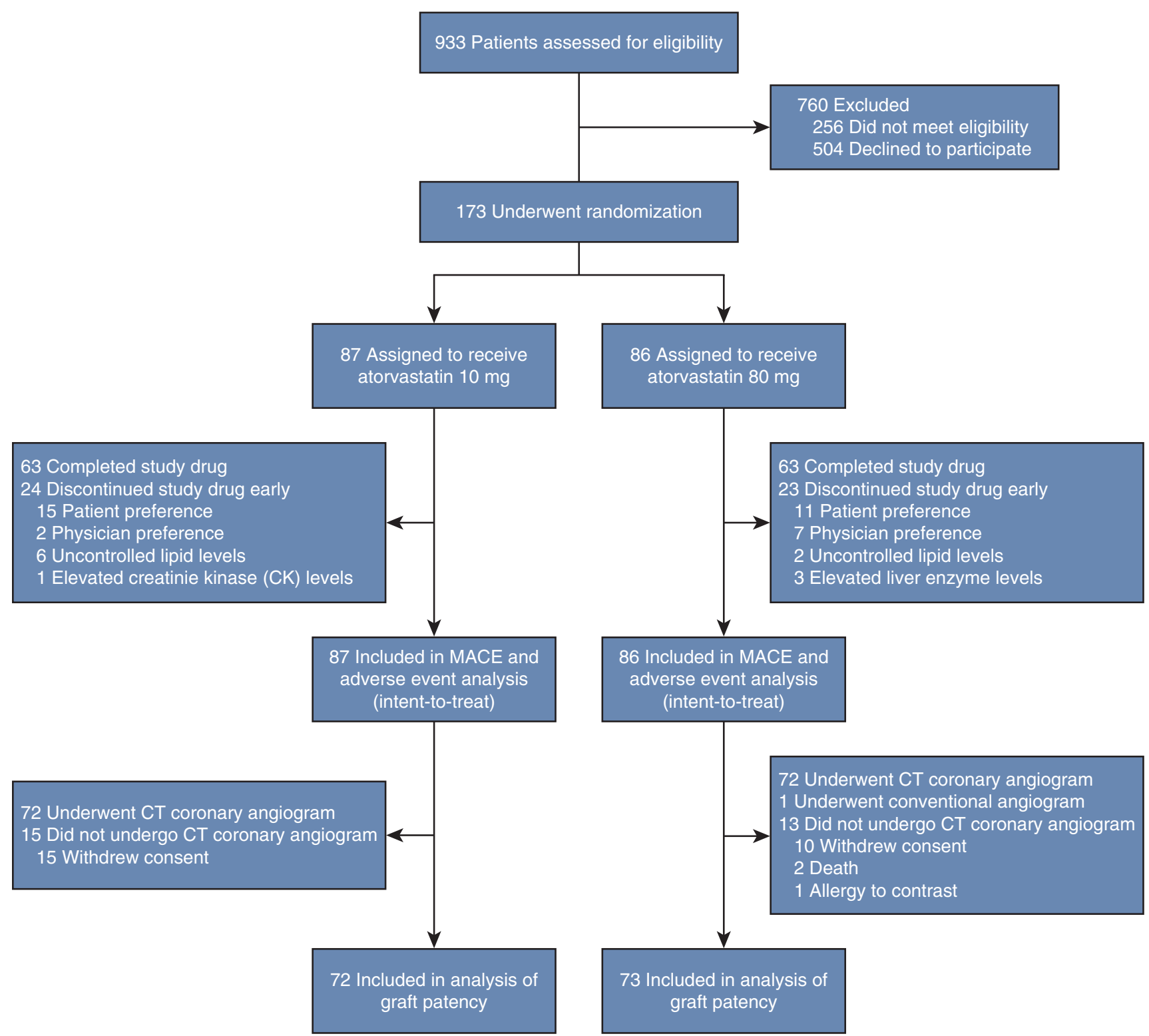

FIGURE 1. Study enrollment and follow-up. $C K$, Creatine kinase; $C T$, computed tomography; $M A C E$, major adverse cardiovascular event.

the $80 \mathrm{mg}$ atorvastatin group $(P=.28)$. Freedom from MACE at 1 year was $97.6 \% \pm 1.7 \%$ in the $10 \mathrm{mg}$ atorvastatin group and $93.7 \% \pm 2.7 \%$ in the $80 \mathrm{mg}$ atorvastatin group $(P=.27)$.

\section{Study Drug Discontinuation}

Adverse events related to treatment occurred in 1 patient $(1.2 \%)$ in the $10 \mathrm{mg}$ atorvastatin group and 3 patients $(3.5 \%)$ in the $80 \mathrm{mg}$ atorvastatin group $(P=.37)$. Elevated CK levels led to study drug discontinuation for 1 patient $(1.2 \%)$ in the $10 \mathrm{mg}$ atorvastatin group. Elevated liver enzymes led to discontinuation for 3 patients $(3.5 \%)$ in the $80 \mathrm{mg}$ atorvastatin group $(0 \%$ vs $3.5 \%$ for $10 \mathrm{mg}$ atorvastatin vs $80 \mathrm{mg}$ atorvastatin; $P=.12$ ). Elevated LDL cholesterol levels $(>115 \mathrm{mg} / \mathrm{dL}$ ) led to unblinding and open label treatment for 6 patients $(6.9 \%)$ in the $10 \mathrm{mg}$ atorvastatin group and 2 patients $(2.3 \%)$ in the $80 \mathrm{mg}$ atorvastatin group $(P=.28)$. Overall, the study drug was permanently discontinued and open label treatment was prescribed for 24 patients $(27.6 \%)$ in the $10 \mathrm{mg}$ atorvastatin group and 23 patients $(26.7 \%)$ in the $80 \mathrm{mg}$ atorvastatin group $(P=1.00)$. The most common reasons for discontinuing the study medication were patient preference (ie, muscle cramps or mild gastrointestinal side effects) or physician insistence on open label treatment. The average duration of study drug administration was similar 
TABLE 1. Patient characteristics

\begin{tabular}{|c|c|c|}
\hline Characteristic & Atorvastatin $10 \mathrm{mg}(\mathrm{n}=\mathbf{8 7})$ & Atorvastatin $80 \mathrm{mg}(\mathrm{n}=86)$ \\
\hline Age, y & $70.5 \pm 10.4$ & $67.3 \pm 10.4$ \\
\hline Male gender & $68(78.2)$ & $73(84.9)$ \\
\hline Body mass index & $29.6 \pm 5.2$ & $29.9 \pm 4.8$ \\
\hline Diabetes mellitus & $38(43.7)$ & $36(41.9)$ \\
\hline Current smoker & $12(13.8)$ & $13(15.1)$ \\
\hline Hypertension & $71(81.6)$ & $73(85.9)$ \\
\hline Hyperlipidemia & $77(88.5)$ & $76(89.4)$ \\
\hline Acute coronary syndrome* & $37(43.0)$ & $38(44.2)$ \\
\hline Previous myocardial infarction & $22(25.3)$ & $17(19.8)$ \\
\hline Previous PCI & $24(27.6)$ & $19(22.1)$ \\
\hline Angina CCS class 3 or 4 & $63(72.4)$ & $51(59.3)$ \\
\hline Heart failure NYHA class 3 or 4 & $36(41.4)$ & $33(38.4)$ \\
\hline Preoperative atrial fibrillation & $11(12.6)$ & $7(8.1)$ \\
\hline Chronic obstructive pulmonary disease & $8(9.2)$ & $4(4.6)$ \\
\hline Cerebrovascular disease & $11(12.6)$ & $6(7.0)$ \\
\hline Peripheral vascular disease & $6(6.9)$ & $5(5.8)$ \\
\hline Preoperative LDL, mg/dL & $83.2 \pm 31.7$ & $80.2 \pm 33.2$ \\
\hline Preoperative creatinine, $\mathrm{mg} / \mathrm{dL}$ & $1.09 \pm 0.24$ & $1.07 \pm 0.23$ \\
\hline \multicolumn{3}{|l|}{ Preoperative medication use } \\
\hline Aspirin & $77(88.5)$ & $73(85.9)$ \\
\hline Clopidogrel & $18(20.7)$ & $15(17.4)$ \\
\hline Statin & $73(83.9)$ & $72(83.7)$ \\
\hline Beta blocker & $67(77.0)$ & $68(79.1)$ \\
\hline ACEI or ARB & $49(57.0)$ & $52(60.5)$ \\
\hline \multicolumn{3}{|l|}{ Operative details } \\
\hline Number of distal anastomoses & $2.7 \pm 0.8$ & $2.9 \pm 0.6$ \\
\hline Left internal thoracic graft & $76(87.4)$ & $81(95.3)$ \\
\hline Second arterial graft & $7(8.0)$ & $17(19.8)$ \\
\hline Crossclamp time, $\min$ & $85.8 \pm 38.3$ & $95.5 \pm 41.3$ \\
\hline Cardiopulmonary bypass time, $\min$ & $117.4 \pm 44.0$ & $128.7 \pm 48.1$ \\
\hline Off-pump surgery & $4(4.6)$ & $6(7.0)$ \\
\hline Concurrent valve & $10(11.5)$ & $11(12.8)$ \\
\hline Endoscopic vein harvest & $73(83.9)$ & $72(83.7)$ \\
\hline
\end{tabular}

Values are presented as $\mathrm{n}(\%)$ or mean \pm standard deviation. PCI, Percutaneous coronary intervention; CCS, Canadian Cardiovascular Society; NYHA, New York Heart Association; $L D L$, low-density lipoprotein level; $A C E I$, angiotensin converting enzyme inhibitor; $A R B$, angiotensin receptor blocker. *Recent acute coronary syndrome within 1 month.

between the 2 groups $(299.2 \pm 115.3$ days vs $297.9 \pm 113.1$ days for $10 \mathrm{mg}$ atorvastatin vs $80 \mathrm{mg}$ atorvastatin; $P=.94)$.

\section{Sensitivity Analysis}

Using logistic regression analysis, no significant association was seen between $80 \mathrm{mg}$ atorvastatin and vein graft occlusion after adjustment for either patient age $(P=.63)$ or mean LDL cholesterol level during the trial $(P=.92)$. The only factor that approached significance in the multivariable model was the use of sequential vein grafting $(P=.18)$
(Table E1). Analysis with generalized estimating equations also did not reveal a significant association between $80 \mathrm{mg}$ atorvastatin and vein graft occlusion $(P=.56)$. Lastly, no significant association between $80 \mathrm{mg}$ atorvastatin and vein graft occlusion was seen after adjusting for stratification factors (eg, surgical center, use of cardiopulmonary bypass, and the presence of diabetes; $P=.69$ ). The perprotocol analysis (focused on the 111 patients who continued the allocated blinded treatment for the entire 1year duration) led to findings similar to the overall study results. In this analysis, the vein graft occlusion rate at 1 year 
TABLE 2. Postoperative course

\begin{tabular}{lccc}
\hline \multicolumn{1}{c}{ Course } & $\begin{array}{c}\text { Atorvastatin } \\
\mathbf{1 0 ~} \mathbf{~} \mathbf{~}(\mathbf{n}=\mathbf{8 7})\end{array}$ & $\begin{array}{c}\text { Atorvastatin } \\
\mathbf{8 0} \mathbf{~ m g}(\mathbf{n}=\mathbf{8 6})\end{array}$ & $\boldsymbol{P}$ value \\
\hline Length of stay & & & \\
$\quad$ Intensive care, d & $2.9 \pm 1.6$ & $2.6 \pm 1.1$ & .09 \\
Hospital, d & $6.7 \pm 2.5$ & $6.2 \pm 2.1$ & .16 \\
Medication at discharge & & & \\
Aspirin & $85(98.8)$ & $80(94.1)$ & .12 \\
Clopidogrel & $10(11.6)$ & $11(12.9)$ & .82 \\
Warfarin & $14(16.3 \%)$ & $12(14.1)$ & .83 \\
Beta blocker & $80(93.0)$ & $76(89.4)$ & .43 \\
ACEI or ARB & $29(33.7)$ & $27(31.8)$ & .87 \\
\hline
\end{tabular}

Values are presented as mean \pm standard deviation or $\mathrm{n}(\%)$. ACEI, Angiotensin converting enzyme inhibitor; $A R B$, angiotensin receptor blocker.

was similar between the 2 groups $(10.9 \%$ vs $12.1 \%$ for $10 \mathrm{mg}$ atorvastatin vs $80 \mathrm{mg}$ atorvastatin; $P=.82$ ) (Table E2).

\section{DISCUSSION}

ACTIVE is the first randomized controlled trial to evaluate the influence of early postoperative high-dose statin therapy on vein graft patency after CABG. Compared with moderate-dose therapy with $10 \mathrm{mg}$ atorvastatin, we found that high-dose therapy with $80 \mathrm{mg}$ atorvastatin significantly lowered LDL cholesterol levels after surgery by $26.1 \%$. However, high-dose statin therapy did not lead to a significant reduction in vein graft occlusion 1 year following surgery. We also did not see a significant difference in vein graft stenosis or MACEs between the 2 treatment groups (Video 1).

SVG disease continues to be among the main limitations of CABG. Elevated cholesterol levels are associated with faster progression of SVG disease after $\mathrm{CABG},{ }^{7,8}$ whereas statin treatment has been shown to slow this process by inhibiting neointimal formation and smooth muscle proliferation. ${ }^{12,26,32}$ The importance of statins after coronary surgery was highlighted in the landmark postCABG trial $^{12,13}$ that compared aggressive cholesterol reduction with lovastatin 40 to $80 \mathrm{mg}$ daily to moderate cholesterol reduction with lovastatin 2.5 to $5 \mathrm{mg}$ daily among 1351 patients. CABG had been performed 1 to 11 years before subject recruitment, and $>50 \%$ of patients had undergone surgery more than 5 years earlier. As measured annually during the study period, mean LDL cholesterol levels of patients who received aggressive treatment ranged from 93 to $97 \mathrm{mg} / \mathrm{dL}$ compared with 132 to $136 \mathrm{mg} / \mathrm{dL}$ for patients who received moderate treatment $(P<.001)$. Aggressive statin therapy resulted in a lower rate of vein graft occlusion on follow-up imaging, ${ }^{12}$ and a significant reduction in clinical events. ${ }^{13}$

Based on the post-CABG trial and other subsequent studies, ${ }^{12-14,33,34}$ clinical guidelines for many years recommended statins after CABG to achieve an LDL cholesterol level treatment goal $<100 \mathrm{mg} / \mathrm{dL} .{ }^{16,17}$ More recently, several cardiology trials have demonstrated that even more intensive lipid reduction with high-dose statin therapy can further improve cardiovascular outcomes. ${ }^{18-21}$ Post hoc subgroup data from the Treating to New Targets (TNT) trial suggested that patients with a history of remote CABG had improved outcomes when treated with $80 \mathrm{mg}$ atorvastatin daily compared with $10 \mathrm{mg}$ atorvastatin daily. ${ }^{18,22}$ Patients with a history of CABG also appeared to benefit with aggressive LDL cholesterol level reduction in the Improved Reduction of Outcomes: Vytorin Efficacy International Trial (IMPROVE-IT),

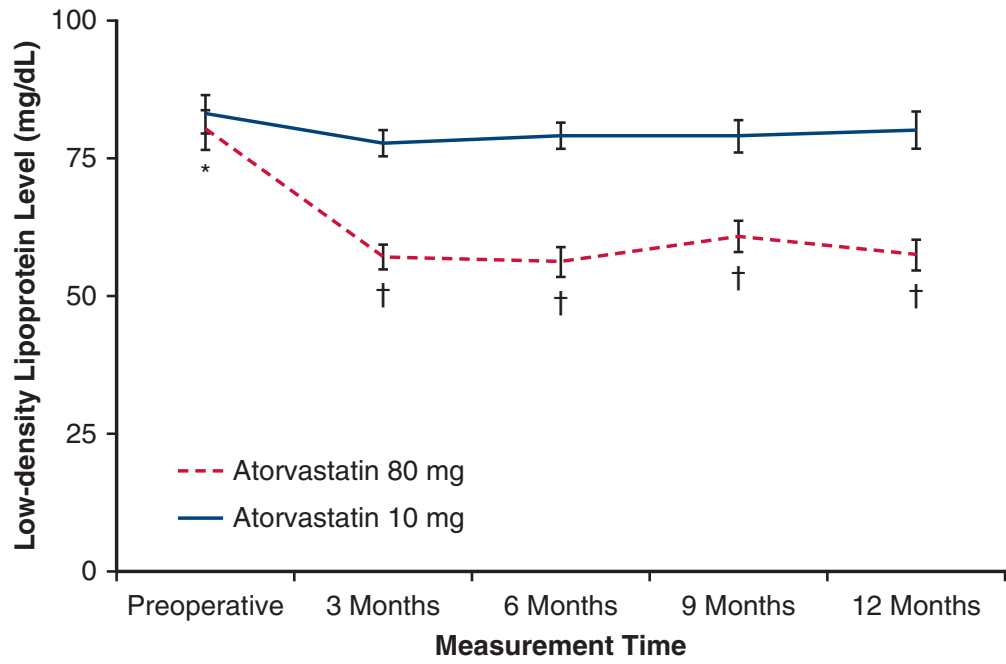

FIGURE 2. Low-density lipoprotein (LDL) levels during study enrollment. LDL levels significantly declined for patients who received $80 \mathrm{mg}$ atorvastatin compared with those who received $10 \mathrm{mg}$ atorvastatin (analysis of variance $P<.0001$ ). $* P=.56$ at baseline preoperative measurement. $\dagger P<.00001$ for measurements at 3 months, 6 months, 9 months, and 12 months. 
TABLE 3. Graft evaluation at 1 year (intention-to-treat analysis)

\begin{tabular}{|c|c|c|c|}
\hline Angiography result* & $\begin{array}{c}\text { Atorvastatin } \\
10 \mathrm{mg}\end{array}$ & $\begin{array}{c}\text { Atorvastatin } \\
80 \mathrm{mg}\end{array}$ & $P$ value \\
\hline Any graft occlusion & $20 / 194(10.3)$ & $20 / 209(9.6)$ & .87 \\
\hline Vein graft occlusion & $16 / 124(12.9)$ & $14 / 123(11.4)$ & .85 \\
\hline Vein graft stenosis & $7 / 124(5.6)$ & $4 / 123(3.2)$ & .54 \\
\hline $\begin{array}{l}\text { Vein graft stenosis or } \\
\text { occlusion }\end{array}$ & $23 / 124(18.5)$ & $18 / 123(14.6)$ & .49 \\
\hline
\end{tabular}

Values are presented as $\mathrm{n} / \mathrm{n}(\%) .{ }^{*}$ Computed tomography coronary angiogram $(n=144)$ or conventional coronary angiogram $(n=1)$.

which focused on combination therapy with simvastatin and ezetemibe. ${ }^{35,36}$ However, no graft patency data were collected in the TNT or IMPROVE-IT surgical substudies. Moreover, patients in these post hoc analyses had undergone CABG many years earlier and likely had evidence of vein graft disease at the time of enrollment. ${ }^{18,22,36} \mathrm{In}$ contrast, high-dose statin therapy was administered early after CABG in the ACTIVE trial, before the development of vein graft disease.

In keeping with the ACTIVE hypothesis, the incidence of vein graft disease in the current trial appeared slightly lower for patients in the $80 \mathrm{mg}$ atorvastatin group, with all vein graft end points favoring high-dose statin treatment, although statistical significance was not achieved. We did note a trend toward fewer patients developing vein graft disease (either occlusion or stenosis) in the $80 \mathrm{mg}$ atorvastatin group $(29.2 \%$ vs $19.2 \% ; P=.18)$, although this was not a prespecified end point. On the other hand, there was a slightly greater incidence of hospitalization for coronary

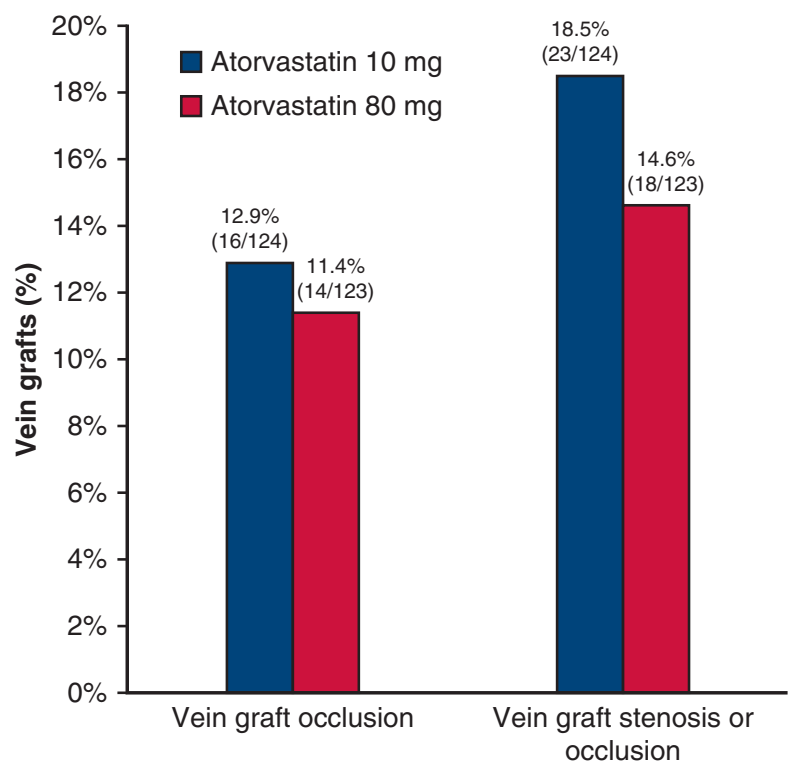

FIGURE 3. Vein graft stenosis or occlusion (intention-to-treat analysis). There was no significant difference in the incidence of vein graft occlusion $(P=.85)$ or the combination of vein graft stenosis and occlusion $(P=.49)$ between the 2 groups. ischemia among the $80 \mathrm{mg}$ atorvastatin group $(P=.12)$. Regardless, whether high-dose statin therapy prevents the long-term progression of vein graft atherosclerosis or improves late graft patency cannot be determined from the current study. This will be the subject of future research from our group.

Few studies to date have evaluated the influence of highdose statins early following surgical coronary revascularization. ${ }^{37}$ Recently, 2 randomized controlled trials evaluated the potential benefits of administering high-dose statin therapy during the perioperative period, yielding neutral results. Initiating high-dose statins before surgery and then continuing them postoperatively did not lead to clinical gains in terms of reducing the risk of perioperative atrial fibrillation, myocardial damage, or acute kidney injury early after CABG. ${ }^{24,25}$ In the ACTIVE trial, we did not evaluate these perioperative outcomes because our focus was on graft patency.

Irrespective of our study results, high-dose statin therapy has become the standard of care for patients who have undergone CABG. Citing several primary and secondary prevention studies that reported benefits with high-dose statins, ${ }^{18,22}$ recent American Heart Association guideline committees recommended high-intensity statin therapy for all patients with clinical atherosclerotic disease, including nearly all patients who have previously undergone CABG. ${ }^{9,31}$ Although the cardiovascular community has been hesitant to adopt these guidelines, ${ }^{38}$ we sought to be compliant with the new recommendations. ${ }^{9,31} \mathrm{We}$ therefore closed the ACTIVE trial early, after having recruited 173 patients instead of 200 as originally planned. Although this may have limited our statistical power, post hoc calculations demonstrated that we had $71 \%$ power to detect a reduction in graft occlusion with high-dose statin therapy from $20 \%$ to $10 \%$, had this difference been present. However, the graft occlusion rate improved only from $12.9 \%$ to $11.4 \%$. Applying these figures to power a future study, we estimate a far larger study would be required to achieve statistical significance, with nearly 650 patients needed in each study arm, and a total of 2500 vein grafts. It is unlikely that such a trial will ever take place, given the cost and the existence of the new guideline recommendations. ${ }^{9,31}$

In addition to the modest sample size, the ACTIVE study has other limitations that should be taken into account when interpreting the results. The atorvastatin doses of $10 \mathrm{mg}$ and $80 \mathrm{mg}$ used in this trial were chosen with the expectation that they would yield average LDL cholesterol levels of $100 \mathrm{mg} / \mathrm{dL}$ and $70 \mathrm{mg} / \mathrm{dL}$, respectively. ${ }^{18}$ However, lower levels were seen with both doses (mean, $79.2 \mathrm{mg} / \mathrm{dL}$ and $58.5 \mathrm{mg} / \mathrm{dL}$, respectively), which could have slowed the development of vein graft atherosclerosis and influenced our ability to demonstrate a difference in graft occlusion between the groups. This, we 
TABLE 4. Clinical outcomes and reasons for study drug discontinuation

\begin{tabular}{|c|c|c|c|}
\hline Outcome & $\begin{array}{c}\text { Atorvastatin } \\
10 \mathrm{mg}(\mathrm{n}=\mathbf{8 7})\end{array}$ & $\begin{array}{c}\text { Atorvastatin } \\
\mathbf{8 0 ~} \mathbf{~ m g ~}(\mathbf{n}=\mathbf{8 6})\end{array}$ & $\begin{array}{c}P \\
\text { value }\end{array}$ \\
\hline Death from any cause & 0 & $2(2.3)^{*}$ & .25 \\
\hline \multicolumn{4}{|l|}{$\begin{array}{l}\text { Major adverse cardiovascular } \\
\text { event }\end{array}$} \\
\hline Cardiovascular death & 0 & $1(1.2)$ & .50 \\
\hline Myocardial infarction & 0 & $1(1.2)$ & .50 \\
\hline Cerebrovascular accident & $2(2.3)$ & $2(2.3)$ & 1.00 \\
\hline $\begin{array}{l}\text { Hospitalization for } \\
\text { coronary ischemia }\end{array}$ & 0 & $3(3.5)$ & .12 \\
\hline $\begin{array}{l}\text { Need for coronary } \\
\text { intervention }\end{array}$ & 0 & $2(2.3)$ & .25 \\
\hline $\begin{array}{l}\text { Any adverse cardiovascular } \\
\text { event }\end{array}$ & $2(2.3)$ & $5(5.8)$ & .28 \\
\hline $\begin{array}{l}\text { Study drug discontinuation } \\
\text { Reason for discontinuation }\end{array}$ & $24(27.6)$ & $23(26.7)$ & 1.00 \\
\hline Patient preference & $15(17.2)$ & $11(12.8)$ & \\
\hline Physician preference & $2(2.3)$ & $7(8.1)$ & \\
\hline Uncontrolled LDL $\dagger$ & $6(6.9)$ & $2(2.3)$ & \\
\hline Elevated CK level $\ddagger$ & $1(1.2)$ & $0(0)$ & \\
\hline $\begin{array}{l}\text { Elevated ALT/AST } \\
\text { level } \S\end{array}$ & 0 & $3(3.5)$ & \\
\hline
\end{tabular}

Values are presented as n (\%). $L D L$, Low-density lipoprotein cholesterol; $C K$, creatine kinase; $A L T$, alanine aminotransferase; $A S T$, aspartate aminotransferase. *Respiratory failure from suspected vasculitis; cardiac arrest following presentation with acute coronary syndrome. $\nmid \mathrm{LDL}$ level $>115 \mathrm{mg} / \mathrm{dL}$ necessitating open label therapy. $\ddagger$ CK level $>10$ times the upper limit of normal with muscle symptoms, or 2 consecutive measurements $>10$ times the upper limit of normal without symptoms. $\S$ Consecutive elevated measurements for ALT or AST $>3$ times the upper limit of normal.

believe, highlights the value of continuing to follow these patients with additional imaging studies beyond the 1year time point. Although no significant difference was seen in this pilot trial, a larger study with a longer period of follow-up could have ultimately demonstrated a

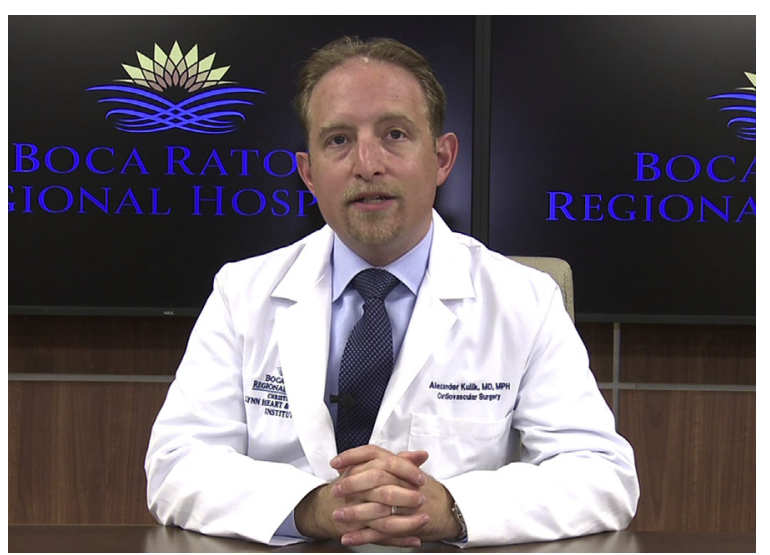

VIDEO 1. The lead author explaining the study and the importance of the article. Video available at: https://www.jtcvs.org/article/S0022-5223(18) 31865-8/fulltext. benefit for intensive statin therapy. It is also unclear whether the use of other high-intensity statin therapies (such as rosuvastatin) could have yielded different results than those seen with atorvastatin in this trial. Furthermore, complete CT coronary angiographic follow-up could not be achieved for all patients recruited in ACTIVE. However, the imaging rate of $84 \%$ compares favorably with other CABG patency trials. ${ }^{39}$ For 6 patients $(6.9 \%)$ in the $10 \mathrm{mg}$ atorvastatin group and $2 \mathrm{pa}-$ tients $(2.3 \%)$ in the $80 \mathrm{mg}$ atorvastatin group, unblinding and uptitration of lipid-lowering therapy was required for elevated LDL cholesterol levels. This escape criterion was incorporated into the trial (after consultation with the Food and Drug Administration) to ensure that all study patients received sufficient LDL cholesterol level reduction after surgery, based on the guidelines at that time. ${ }^{16,17}$ Finally, a total of 47 patients $(27.2 \%)$ in ACTIVE prematurely discontinued the study medication based on personal preference $(15.0 \%)$, physician insistence $(5.2 \%)$, or safety concerns $(6.9 \%)$. Although somewhat elevated, high rates of study drug discontinuation have previously been reported for clinical trials evaluating aggressive LDL cholesterol level reduction therapies. ${ }^{20,21,35}$ In the Aggrastat to Zocor trial, the reported discontinuation rate was $34 \%,{ }^{21}$ whereas it was $42 \%$ in the IMPROVE-IT trial. ${ }^{35}$ Regardless, the per-protocol analysis in ACTIVE yielded similar results to those seen with the inclusion of all randomized patients (intention-to-treat).

\section{CONCLUSIONS}

The ACTIVE pilot trial indicated that, compared with medium-dose statin therapy with $10 \mathrm{mg}$ atorvastatin daily, early postoperatively high-dose statin therapy with $80 \mathrm{mg}$ atorvastatin daily did not significantly reduce vein graft occlusion 1 year after CABG.

\section{Webcast}

You can watch a Webcast of this AATS meeting presentation by going to: https://aats.blob.core.windows.net/ media/18Apr30/28ABC\%20Controversies \% 20in \% 20CABG/ S66\%20-\%20Part\%202/S66_12_webcast_054053654.mp4.

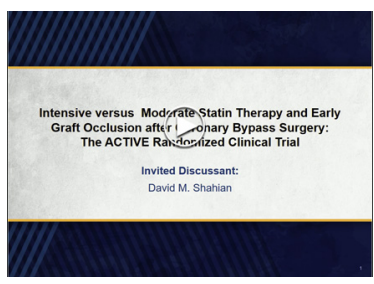

\section{Conflict of Interest Statement}

Authors have nothing to disclose with regard to commercial support. 


\section{References}

1. Schwann TA, Tatoulis J, Puskas J, Bonnell M, Taggart D, Kurlansky P, et al. Worldwide trends in multi-arterial coronary artery bypass grafting surgery 2004-2014: a tale of 2 continents. Semin Thorac Cardiovasc Surg. 2017;29: 273-80.

2. Bakaeen FG, Blackstone EH, Pettersson GB, Gillinov AM, Svensson LG. The father of coronary artery bypass grafting: Rene Favaloro and the 50th anniversary of coronary artery bypass grafting. J Thorac Cardiovasc Surg. 2018;155:2324-8.

3. Stouffer CW, Halkos ME. Oh, father, where art we? Left internal mammary artery with greater saphenous vein grafts still rules surgical coronary revascularization after 30 years. J Thorac Cardiovasc Surg. 2018;155:2329-30.

4. Motwani JG, Topol EJ. Aortocoronary saphenous vein graft disease: pathogenesis, predisposition, and prevention. Circulation. 1998;97:916-31.

5. Bourassa MG. Fate of venous grafts: the past, the present and the future. J Am Coll Cardiol. 1991;17:1081-3.

6. Fitzgibbon GM, Kafka HP, Leach AJ, Keon WJ, Hooper GD, Burton JR. Coronary bypass graft fate and patient outcome: angiographic follow-up of 5,065 grafts related to survival and reoperation in 1,388 patients during 25 years. $J$ Am Coll Cardiol. 1996;28:616-26.

7. Campeau L, Enjalbert M, Lesperance J, Bourassa MG, Kwiterovich P Jr, Wacholder S, et al. The relation of risk factors to the development of atherosclerosis in saphenous-vein bypass grafts and the progression of disease in the native circulation. A study 10 years after aortocoronary bypass surgery. $N$ Engl J Med. 1984;311:1329-32.

8. Daida H, Yokoi H, Miyano H, Mokuno H, Satoh H, Kottke TE, et al. Relation of saphenous vein graft obstruction to serum cholesterol levels. J Am Coll Cardiol. 1995;25:193-7.

9. Kulik A, Ruel M, Jneid H, Ferguson TB, Hiratzka LF, Ikonomidis JS, et al. Secondary prevention after coronary artery bypass graft surgery: a scientific statement from the American Heart Association. Circulation. 2015;131:927-64.

10. Kulik A. Secondary prevention after coronary artery bypass graft surgery: a primer. Curr Opin Cardiol. 2016;31:635-43.

11. Hage A, Voisine P, Erthal F, Larose E, Glineur D, Chow B, et al. Eight-year follow-up of the Clopidogrel After Surgery for Coronary Artery Disease (CASCADE) trial. J Thorac Cardiovasc Surg. 2018;155:212-22.e2.

12. The effect of aggressive lowering of low-density lipoprotein cholesterol levels and low-dose anticoagulation on obstructive changes in saphenous-vein coronary-artery bypass grafts. The Post Coronary Artery Bypass Graft Trial Investigators. N Engl J Med. 1997;336:153-62.

13. Knatterud GL, Rosenberg Y, Campeau L, Geller NL, Hunninghake DB, Forman SA, et al. Long-term effects on clinical outcomes of aggressive lowering of low-density lipoprotein cholesterol levels and low-dose anticoagulation in the post coronary artery bypass graft trial. Post CABG Investigators. Circulation. 2000;102:157-65.

14. Kulik A, Brookhart MA, Levin R, Ruel M, Solomon DH, Choudhry NK. Impact of statin use on outcomes after coronary artery bypass graft surgery. Circulation. 2008;118:1785-92.

15. Kulik A, Ruel M. Lipid-lowering therapy and coronary artery bypass graft surgery: what are the benefits? Curr Opin Cardiol. 2011;26:508-17.

16. Eagle KA, Guyton RA, Davidoff R, Edwards FH, Ewy GA, Gardner TJ, et al. ACC/AHA 2004 guideline update for coronary artery bypass graft surgery: a report of the American College of Cardiology/American Heart Association Task Force on Practice Guidelines (Committee to Update the 1999 Guidelines for Coronary Artery Bypass Graft Surgery). Circulation. 2004;110:e340-437.

17. Smith SC Jr, Allen J, Blair SN, Bonow RO, Brass LM, Fonarow GC, et al. AHA/ ACC guidelines for secondary prevention for patients with coronary and other atherosclerotic vascular disease: 2006 update: endorsed by the National Heart, Lung, and Blood Institute. Circulation. 2006;113:2363-72.

18. LaRosa JC, Grundy SM, Waters DD, Shear C, Barter P, Fruchart JC, et al. Intensive lipid lowering with atorvastatin in patients with stable coronary disease. $N$ Engl J Med. 2005;352:1425-35.

19. Pedersen TR, Faergeman O, Kastelein JJ, Olsson AG, Tikkanen MJ, Holme I, et al. High-dose atorvastatin vs usual-dose simvastatin for secondary prevention after myocardial infarction: the IDEAL study: a randomized controlled trial. JAMA. 2005;294:2437-45.

20. Cannon CP, Braunwald E, McCabe CH, Rader DJ, Rouleau JL, Belder R, et al. Intensive versus moderate lipid lowering with statins after acute coronary syndromes. N Engl J Med. 2004;350:1495-504.
21. de Lemos JA, Blazing MA, Wiviott SD, Lewis EF, Fox KA, White HD et al. Early intensive vs a delayed conservative simvastatin strategy in patients with acute coronary syndromes: phase $\mathrm{Z}$ of the $\mathrm{A}$ to $\mathrm{Z}$ trial. JAMA 2004;292:1307-16

22. Shah SJ, Waters DD, Barter P, Kastelein JJ, Shepherd J, Wenger NK, et al. Intensive lipid-lowering with atorvastatin for secondary prevention in patients after coronary artery bypass surgery. J Am Coll Cardiol. 2008;51:1938-43.

23. Kulik A, Ruel M. Statins and coronary artery bypass graft surgery: preoperative and postoperative efficacy and safety. Expert Opin Drug Saf. 2009;8:559-71.

24. Billings FT, Hendricks PA, Schildcrout JS, Shi Y, Petracek MR, Byrne JG, et al High-dose perioperative atorvastatin and acute kidney injury following cardiac surgery: a randomized clinical trial. JAMA. 2016;315:877-88.

25. Zheng Z, Jayaram R, Jiang L, Emberson J, Zhao Y, Li Q, et al. Perioperative rosuvastatin in cardiac surgery. N Engl J Med. 2016;374:1744-53.

26. Kulik A, Voisine P, Mathieu P, Masters RG, Mesana TG, Le May MR, et al. Statin therapy and saphenous vein graft disease after coronary bypass surgery: analysis from the CASCADE randomized trial. Ann Thorac Surg. 2011;92:1284-90; discussion 1290-1.

27. Hata M, Takayama T, Sezai A, Yoshitake I, Hirayama A, Minami K. Efficacy of aggressive lipid controlling therapy for preventing saphenous vein graft disease. Ann Thorac Surg. 2009;88:1440-4.

28. Kulik A, Abreu AM, Boronat V, Ruel M. Intensive versus moderate atorvastatin therapy and one-year graft patency after $\mathrm{CABG}$ : rationale and design of the ACTIVE (Aggressive Cholesterol Therapy to Inhibit Vein Graft Events) randomized controlled trial (NCT01528709). Contemp Clin Trials. 2017;59:98-104.

29. Kulik A, Chan V, Ruel M. Antiplatelet therapy and coronary artery bypass graf surgery: perioperative safety and efficacy. Expert Opin Drug Saf. 2009;8:169-82.

30. Jones CM, Athanasiou T, Dunne N, Kirby J, Aziz O, Haq A, et al. Multi-detector computed tomography in coronary artery bypass graft assessment: a meta-analysis. Ann Thorac Surg. 2007;83:341-8.

31. Stone NJ, Robinson JG, Lichtenstein AH, Bairey Merz CN, Blum CB, Eckel RH et al. 2013 ACC/AHA guideline on the treatment of blood cholesterol to reduce atherosclerotic cardiovascular risk in adults: a report of the American College of Cardiology/American Heart Association Task Force on Practice Guidelines. Circulation. 2014;129:S1-45.

32. Yang Z, Kozai T, van der Loo B, Viswambharan H, Lachat M, Turina MI, et al HMG-CoA reductase inhibition improves endothelial cell function and inhibits smooth muscle cell proliferation in human saphenous veins. J Am Coll Cardiol. 2000;36:1691-7.

33. Christenson JT. Preoperative lipid control with simvastatin protects coronary artery bypass grafts from obstructive graft disease. Am J Cardiol. 2001;88: 896-9.A8.

34. Gan HL, Zhang JQ, Bo P, Wang SX, Lu CS. Statins decrease adverse outcomes in coronary artery bypass for extensive coronary artery disease as well as left main coronary stenosis. Cardiovasc Ther. 2010;28:70-9.

35. Cannon CP, Blazing MA, Giugliano RP, McCagg A, White JA, Theroux P, et al. Ezetimibe added to statin therapy after acute coronary syndromes. $N$ Engl J Med. 2015;372:2387-97.

36. Eisen A, Cannon CP, Blazing MA, Bohula EA, Park JG, Murphy SA, et al. The benefit of adding ezetimibe to statin therapy in patients with prior coronary artery bypass graft surgery and acute coronary syndrome in the IMPROVE-IT trial. Eur Heart J. 2016;37:3576-84.

37. Ouattara A, Benhaoua H, Le Manach Y, Mabrouk-Zerguini N, Itani O, Osman A et al. Perioperative statin therapy is associated with a significant and dosedependent reduction of adverse cardiovascular outcomes after coronary artery bypass graft surgery. J Cardiothorac Vasc Anesth. 2009;23:633-8.

38. Pokharel Y, Tang F, Jones PG, Nambi V, Bittner VA, Hira RS, et al. Adoption of the 2013 American College of Cardiology/American Heart Association cholesterol management guideline in cardiology practices nationwide. JAMA Cardiol. 2017;2:361-9.

39. Kulik A, Le May MR, Voisine P, Tardif JC, Delarochelliere R, Naidoo S, et al Aspirin plus clopidogrel versus aspirin alone after coronary artery bypass grafting: the Clopidogrel After Surgery for Coronary Artery Disease (CASCADE) trial. Circulation. 2010;122:2680-7.

Key Words: coronary artery bypass graft surgery, statin therapy, saphenous vein graft 


\section{Discussion}

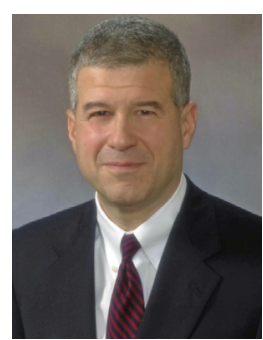

Dr David Shahian (Boston, Mass). Congratulations, Dr Kulik, on a very nicely presented study. You and your colleagues have studied the use of high- versus low-intensity statins to reduce stenosis or occlusion of saphenous vein grafts, which, interestingly, in either arm of the current study had 1 -year patency rates roughly equal to the 10 -year patency rates of internal thoracic artery grafts-but that's a story for another day. The results of the study are inconclusive because it was substantially underpowered to detect differences of the unexpectedly small magnitude that were observed. I have several questions.

First, despite block randomization and stratification adjustment, there were fairly striking differences between the 2 groups in surgical technique, even if they were not statistically significant due to the small sample sizes. For example, in the low-intensity group, only $87 \%$ of patients received a left internal thoracic artery graft, which is certainly inconsistent with current coronary artery bypass grafting practice; the rate in the high-intensity group was about $95 \%$. So it appeared to me that randomization in this case resulted in 2 very different groups, at least based on this important marker of good surgical technique. I wonder if you could comment on that finding.

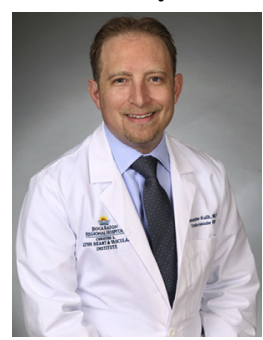

Dr Kulik (Boca Raton, Fla). Thank you very much for your kind comments and your question. Regarding randomization, if you examine patient characteristics between groups in any clinical trial, you will find significance, on average, for 1 in 20 characteristics $(P<.05)$. Most of the baseline characteristics in this trial were very well balanced. The only characteristics that were significant between the 2 groups were age and the more frequent use of a second arterial graft for the high-dose statin group.

Your question regarding internal thoracic artery use is a good one. Just to clarify, all patients in the study underwent coronary artery bypass grafting surgery, but a number of patients also underwent concomitant valve surgery. Some of the patients recruited in the study underwent aortic valve replacement, with a vein graft to the right coronary or to the circumflex. With no left anterior descending artery disease, no left internal thoracic artery was used by the operating surgeon. So that was the major reason why a thoracic artery graft was not necessarily used for a few patients. Also, there were 3 patients in the study who received vein grafts to the left anterior descending artery, and this related to emergency circumstances (ie, ongoing cardiopulmonary resuscitation) or poor quality and nonusable internal thoracic artery grafts.
Dr Shahian. Thank you very much. Eighty-four percent of the patients in both groups were on a preoperative statin, and, as you pointed out, both groups achieved preoperative low-density lipoprotien levels in the low $80 \mathrm{mg} / \mathrm{dLs}$, very close to your target levels, which probably accounts for the smaller than expected vein graft patency differences between the 2 groups. Do you happen to know the doses of statins that those patients were on preoperatively? And I would be curious as to whether randomization resulted in any patients actually going from a higher to a lower dose of statin?

Dr Kulik. High-dose statin therapy in the cardiology literature is defined as 40 or $80 \mathrm{mg}$ atorvastatin and $20 \mathrm{mg}$ or $40 \mathrm{mg}$ rosuvastatin, which can achieve a low-density lipoprotein cholesterol reduction $>50 \%$. Approximately $28 \%$ in the high-dose randomization group and $28 \%$ in the low-dose group were receiving high-intensity statin therapy before surgery. So $28 \%$ actually went from high to low as part of the randomization process. But given the high rate of preoperative statin therapy among the study patients, and the other lipid-lowering reduction therapies that some patients were taking before trial enrollment, your point is well taken; low-density lipoprotein cholesterol levels were lower than expected at the start of the study. They were fairly well controlled by today's standards.

Dr Shahian. The fact that some patients in the study actually went from high-intensity to low-intensity statins relates to my next question.

In the middle of the randomization period from 2012 to January of 2016, when I believe enrollment stopped, there were 2 class $1 \mathrm{~A}$ recommendations released. One, the American College of Cardiology/American Heart Association general cholesterol guidelines, recommended high-intensity statin therapy for all patients with clinical atherosclerotic cardiovascular disease, which all your patients certainly had. That guideline was approved in November 2013 and then published in July of 2014. You were subsequently Chair of the American Heart Association scientific writing committee for secondary prevention postcoronary artery bypass grafting, which very explicitly recommended high-intensity statins for all postcoronary artery bypass grafting patients. This was approved in December 2014 and published in March 2015, yet enrollment in your vein graft study continued for quite some time after that. I was wondering how you navigated the ethical issue of equipoise regarding vein graft patency, but lack of equipoise regarding other published recommendations for secondary prevention in postcoronary artery bypass grafting patients, all of whom in your study would theoretically have benefitted from highintensity statins.

Dr Kulik. That's a great question and a point well taken. Marc Ruel and I, the coauthors on the study, were intimately involved with the development of guideline recommendations for postcoronary artery bypass grafting secondary 
preventive therapy, and we had a good understanding of the studies that formed the basis for the guideline recommendations. That being said, The Aggressive Cholesterol Therapy to Inhibit Vein Graft Events trial is, to our knowledge, the only study that has ever evaluated the influence of highdose statin therapy initiated early after coronary artery bypass grafting on the outcome of vein graft patency. So we felt at the time, despite the guideline recommendations and being so close to the finish line in terms of recruitment, that there was incremental value and knowledge to be gained by continuing the study. But enrollment was very slow, and over the course of approximately 1 year, our group of investigators and our referring cardiologists grew increasingly uncomfortable. Ultimately, we decided to close the study.

That being said, there was a recent American College of Cardiology study ${ }^{\mathrm{E} 1}$ that evaluated the adoption of these guidelines, and the uptake has been very modest. In the current era, among patients who have atherosclerotic disease who are candidates for high-dose statin therapy, only $66 \%$ actually receive high-dose statin therapy from their clinicians.

We sought to be compliant with the recommendations and, ultimately, given the issues I mentioned, we decided to close the trial early.

Dr Shahian. I hope that, during the period after the new guidelines were implemented, while you were still enrolling patients, that those patients were advised they might receive statin therapy that was not consistent with class $1 \mathrm{~A}$ guidelines.

Dr Kulik. All patients completed written informed consent forms, and of course we were under the supervision of research ethics boards at both institutions, but that specific comment was not mentioned to patients being enrolled in the study. From March 2015 (when the postcoronary artery bypass grafting secondary prevention guidelines were published) until the study was closed in January 2016, only a handful of patients were recruited. We felt comfortable up until a certain point, then ultimately decided to close the trial.

Dr Shahian. Thank you very much. 
TABLE E1. Multivariable logistic model for the outcome of vein graft occlusion

\begin{tabular}{lc}
\hline \multicolumn{1}{c}{ Characteristic } & Multivariable analysis \\
\hline Sequential vein graft & Adjusted odds ratio, $2.1 ; 95 \%$ \\
& confidence interval, $0.7-6.1 ;$ \\
& $P=.18$ \\
Study group* & Adjusted odds ratio, 1.2; 95\% \\
& confidence interval, $0.5-2.5 ;$ \\
& $P=.71$ \\
\hline
\end{tabular}

Factors considered in the model include age, gender, preoperative body mass index, diabetes mellitus, smoking, recent acute coronary syndrome, preoperative hypercholesterolemia, preoperative and mean study low-density lipoprotein levels, preoperative target vessel stenosis, off-pump surgery, endoscopic vein harvesting, sequential vein grafting (vs interposition grafting), and the use of a second arterial graft. *Study group was forced into the model.

\section{E-Reference}

E1. Pokharel Y, Tang F, Jones PG, Nambi V, Bittner VA, Hira RS, et al. Adoption of the 2013 American College of Cardiology/American Heart Association Cholesterol Management Guideline in Cardiology Practices Nationwide. JAMA Cardiol. 2017;2:361-9.

TABLE E2. Graft evaluation at 1 year (per-protocol analysis)

\begin{tabular}{lccc}
\hline \multicolumn{1}{c}{ Angiography result } & Atorvastatin $\mathbf{1 0}$ mg & Atorvastatin 80 mg & \multicolumn{1}{c}{$\boldsymbol{P}$ value } \\
\hline Any graft occlusion & $12 / 145(8.3)$ & $16 / 168(9.5)$ & .84 \\
Vein graft occlusion & $10 / 92(10.9)$ & $12 / 99(12.1)$ & .82 \\
Vein graft stenosis & $5 / 92(5.4)$ & $2 / 99(2.0)$ & .26 \\
Vein graft disease (stenosis or occlusion) & $15 / 92(16.3)$ & $14 / 99(14.1)$ & .69 \\
\hline
\end{tabular}

Values are presented as $\mathrm{n} / \mathrm{n}(\%)$. 